\title{
Resident Learning Curve for Laparoscopic Appendectomy According to Seniority
}

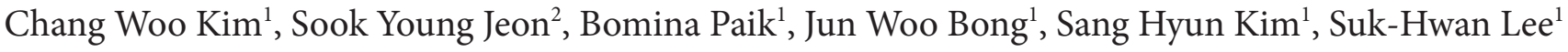 \\ ${ }^{1}$ Department of Surgery, Kyung Hee University Hospital at Gangdong, Kyung Hee University School of Medicine, Seoul; ${ }^{2}$ Department of \\ General Surgery, Graduate School of Medicine, Kyung Hee University, Seoul, Korea
}

Purpose: This study sought to delineate the learning curve (LC) for laparoscopic appendectomy (LA) in surgical residency according to seniority and experience.

Methods: Between October 2015 and November 2016, 150 patients underwent LA performed by one of 3 residents (who were in their first $[A]$, second $[B]$, or third $[C]$ year of training) under supervision. The patients were nonrandomly assigned to each resident. Data from a prospectively collected database were reviewed and analyzed retrospectively. Perioperative outcomes including operation time, complications, and conversion were compared among the 3 residents. The LC was evaluated using the moving average method and cumulative sum control chart (CUSUM) for operation time and surgical completion.

Results: Baseline characteristics and perioperative outcomes were similar among the 3 groups except for age and location of the appendix. The operation time did not vary among the 3 residents $(43.9,45.3$, and 48.4 minutes for $\mathrm{A}, \mathrm{B}$, and $\mathrm{C}$, respectively; $\mathrm{P}=0.392$ ). The moving average method for operation time showed a decreasing tendency for all residents. CUSUM results for operation time revealed peak points achieved at the 24th, 18th, and 31st cases for residents A, B, and C, respectively. In terms of surgical failure, residents $\mathrm{A}, \mathrm{B}$, and $\mathrm{C}$ reached steady states after their 35 th, 11th, and 16th cases, respectively. Perforation of the appendix base was the only risk factor for surgical failure.

Conclusion: The resident LC for LA was 11 to 35 cases according to multidimensional statistical analyses. The accumulation of surgical experience among residents might influence the LC for surgical completion but not that for operation time.

Keywords: Laparoscopic appendectomy; Learning curve; Residency; Education

\section{INTRODUCTION}

Education and training content for surgical residents and trainees includes history-taking, physical examination, treatment planning, surgical technique, and perioperative management. Among these aspects, the evaluation of residents' surgical technique is

Received: March 30, 2019 - Accepted: July 20, 2019

Correspondence to: Suk-Hwan Lee, M.D.

Department of Surgery, Kyung Hee University Hospital at Gangdong, Kyung Hee University School of Medicine, 892 Dongnam-ro, Gangdong-gu, Seoul 05278, Korea

Tel: + 82-2-440-6134, Fax: +82-2-440-6073, E-mail: leeshdr@gmail.com ORCID: https://orcid.org/0000-0001-6470-8620

(C) 2020 The Korean Society of Coloproctology

This is an open-access article distributed under the terms of the Creative Commons Attribution NonCommercial License (https://creativecommons.org/licenses/by-nc/4.0) which permits unrestricted noncommercial use, distribution, and reproduction in any medium, provided the original work is properly cited. crucial to validate their completion of education and training. Acute appendicitis is one of the most common diseases that surgeons encounter, and appendectomy has been ranked first among general surgical emergencies that occur in Korea [1]. Appendectomy is frequently conducted by surgical residents, so it can be a barometer for competency in basic surgical techniques among surgical residents [2-5]. Since Semm [6] reported the outcomes of laparoscopic appendectomy (LA), most appendectomies have been performed via laparoscopy. Better short-term outcomes such as less postoperative pain, shorter hospital stay, and earlier return to daily life as well as improved safety and feasibility have been demonstrated following using the laparoscopic approach to treat appendicitis over the conventional open procedure in several reports [7-10]. Therefore, LA can serve as an evaluation standard for the education and training of surgical residents.

Several reports have already highlighted LA as a viable assess- 
ment of education for surgical residents. Among them were reports showing that surgery performed by residents resulted in similar clinical outcomes as those following surgery conducted by attending or supervising surgeons [11-13]. Others have sought to delineate the learning curve (LC) for LA performed by residents [14-17]. However, limitations in this regard existed such as the heterogeneity of surgical residents, choosing and dividing enrolled patients arbitrarily without proper statistical methods, and a retrospective design.

The aims of the present study were to delineate the LC for LA performed by surgical residents using a multidimensional statistical analysis and to assess surgical technique advancement according to seniority based on residency year.

\section{METHODS}

\section{Patients}

We reviewed medical records from a prospectively created database between October 2015 and November 2016. Consecutive patients who were diagnosed with acute, uncomplicated appendicitis by clinical manifestation, laboratory studies, and imaging studies at Kyung Hee University Hospital at Gangdong in Seoul, Korea were included in this study. Among these patients, 3 surgical residents performed a total of 150 LAs (50 cases each). The patients were nonrandomly assigned to each resident according to their availability and on-duty schedule. If none of the 3 residents were available or on-duty, the patients underwent surgery performed by staff surgeons or other residents and were not included in this study.

We conducted this study in compliance with the principles of the Declaration of Helsinki. The study's protocol was reviewed and approved by the Institutional Review Board (IRB) of Kyung Hee University Hospital at Gangdong (IRB No. KHNMC 201701-026). The need for informed consent was waived. The patients were selected consecutively according to the following inclusion criteria: age from 18 to 80 years old, American Society of Anesthesiologists (ASA) score of III points or less, and acute uncomplicated appendicitis diagnosed with abdominal computed tomography scan or ultrasonography. Patients with high-risk factors for anesthesia or surgery (e.g., ASA score of more than 3 points, pregnancy, mean blood pressure of less than $70 \mathrm{mmHg}$ ) were excluded and underwent surgery conducted by supervising surgeons. To ensure patient safety, those who were suspected to have an intra-abdominal abscess, generalized peritonitis, or malignancy on preoperative imaging studies were also excluded from this research. When the safety of the patient was called into question during the operation, the supervising surgeon intervened and completed the operation. The supervisors were all staff surgeons who had performed more than 100 LAs each previously.

Patient demographic data including sex, age, body mass index (BMI), previous abdominal surgery, past medical history, ASA score, time of symptoms onset, fever, and intraoperative data in- cluding operation time (OT), estimated blood loss, location of the appendix, severity of inflammation, perforation, degree of peritonitis, amount of fluid collection, intraoperative complications, conversion to open surgery, drain placement, and intervention by a supervisor were recorded. OT was recorded in 3 increments during the procedure: skin incision and trocar insertion (open), intra-abdominal procedures and specimen retrieval (intra-abdominal), and wound closure (closure). The location of the appendix was divided into 4 groups: prececal or preileal, subcecal, retrocecal, and pelvic [18]. The amount of fluid collection was assessed during operation as none, minimal (small amount around the appendix), moderate (beyond the appendix and including the paracolic gutter, subhepatic space, or pelvis), and profuse (huge amount of generalized fluid collection).

The supervisor intervened in the surgery when a patient's safety could not be guaranteed (e.g., due to massive adhesion, severe inflammation, presence of an abscess more severe than shown on preoperative imaging, other situation that required conversion to open surgery). If a supervisor intervened for any reason, the surgery was regarded as a surgical failure and the case was excluded from analysis of the LC for OT. Postoperative outcomes were analyzed, including first bowel movement, first soft diet, length of hospital stay, postoperative complications within 30 days after surgery, pathologic results, size of the appendix, and readmission within 30 days after surgery. To assess the safety of surgery performed by residents, demographics and perioperative outcomes were compared between cases where the surgery was performed by a resident and those that were performed by staff surgeons during the same study period.

\section{Korean surgical residency training system}

In Korea, 1 year of rotating internship followed by 4 years of general residency is required for the education and training of general surgeons after graduation from a program of 6 to 8 years of undergraduate education. As part of this, there is a general surgical training program defined by the Korean Surgical Society that includes the management of hospitalized patients, out-patients, and emergency cases. In addition, there are obligations to submit operation records, participate in conferences, and take qualification examinations. Overall, surgical residents are expected to participate in at least 100 operations per year and are obligated to perform minor and major operations such as appendectomy, hemorrhoidectomy, cholecystectomy, gastrectomy, and colectomy. Firstyear residents participate in workshops covering basic surgical skills (e.g., suture, tie, aseptic management, dressing), while second-year residents learn basic laparoscopic skills such as trocar insertion, controlling a camera, grasping and third- and fourthyear residents learn advanced laparoscopic techniques.

\section{Residents}

3 surgical residents (A, B, and C) participated in this study voluntarily out of a total of 8 surgical residents in training. Each per- 
formed 50 cases of laparoscopic surgery for acute appendicitis. Resident A (first-year resident) participated in 96 general surgeries before starting this study. Among them, she had scrubbed 19 cases of appendectomy and performed 4 laparoscopic appendectomies. Resident B (second-year resident) had participated in 272 general surgeries before starting this study. Among them, she had scrubbed 42 cases of appendectomy and performed 3 laparoscopic appendectomies. Resident $C$ (third-year resident) had participated in 510 general surgeries before starting this study. Among them, he had scrubbed 98 cases of appendectomy and performed 4 laparoscopic appendectomies.

\section{Surgical technique}

After the patient was placed in a supine position under general anesthesia, a 10-mm trocar was inserted into the infraumbilical area for a camera and pneumoperitoneum was induced with $\mathrm{CO}_{2}$ gas. Two 5-mm trocars were then inserted, including one in the left lower quadrant and one in the suprapubic area. After identification of the tip of the appendix, a mesoappendiceal dissection was performed with monopolar electrocauterization and/or an energy device (Ligasure, Covidien, Dublin, Ireland). The ligation of an appendiceal artery was performed with Ligasure. The root of the appendix was ligated with 2 Endoloops (Ethicon, Somerville, NJ, USA) and resected. The appendix was retrieved using a Lapbag (Sejong Medical, Paju, Korea) through the infraumbilical trocar site. When the trocar site was suspected to be contaminated by the inflamed appendix, irrigation of the site with normal saline was performed. A closed suction drain was inserted if needed.

\section{Statistical analysis}

Continuous variables were analyzed by one-way analysis of variance and categorical variables were analyzed using the chisquared test or Fisher exact test, with P-values of less than 0.05 considered to be statistically significant. The LC for OT was evaluated by the moving average method and cumulative sum control chart (CUSUM), while the LC for surgical completion was evaluated by CUSUM. The methodology used for the statistical analysis has been described in detail in previous reports $[19,20]$. We applied the moving average method to the OT with an order of 15 cases as follows:

$$
\text { MAn }=\frac{x_{n}+x_{n+1}+x_{n+2}+\cdots+x_{n+14}}{15}
$$

The CUSUM procedure is a sequential analysis technique designed to detect changes in a parameter of the probability distribution. We referred the OT and surgical failure for CUSUM as follows ( $\mathrm{xi}=$ the values of each case, $\mu=$ the mean overall value):

$$
\text { CUSUM }=\sum_{i=1}^{n}\left(x_{i}-\mu\right)
$$

Surgical failure was defined as the presence of any of the following: conversion, intervention by a supervisor, postoperative complications, or readmission within 30 days after surgery. The ac- ceptable failure rate was set as $10 \%$. Surgical failure resulted in a decline in the CUSUM graph; otherwise, the CUSUM ascended graphically as successful surgeries accrued. Univariate analysis was performed to identify factors predicting surgical failure using a logistic regression analysis. All statistical analyses were performed using the SPSS ver. 18.0 (SPSS Inc., Chicago, IL, USA).

\section{RESULTS}

\section{Patients}

During the study period, 462 patients underwent surgery for acute appendicitis at our institution. Among them, a number of patients who were suspected to have perforated appendicitis with intra-abdominal abscess on imaging studies $(n=22)$ or malignancy $(n=6)$, those who were outside the age range specified by the inclusion criteria $(n=120)$, and those who were pregnant $(n=2)$ were excluded. Another 162 patients who initially met the inclusion criteria were ultimately excluded due to the participating residents being off-duty or otherwise not available at the time of these patients' procedures. Among the excluded 318 patients, supervisors performed 239 surgeries and the other 7 residents performed 79 surgeries.

The mean age of all included patients was 40.9 years old and 78

Table 1. Patient characteristics and perioperative outcomes

\begin{tabular}{lcccc}
\hline Characteristic & $\mathrm{A}(\mathrm{n}=50)$ & $\mathrm{B}(\mathrm{n}=50)$ & $\mathrm{C}(\mathrm{n}=50)$ & P-value \\
\hline Male sex & $24(48)$ & $23(46)$ & $31(62)$ & 0.262 \\
Age (yr) & $40.3 \pm 14.4$ & $37.9 \pm 13.8$ & $44.5 \pm 15.9$ & $0.085^{\mathrm{a}}$ \\
BMI (kg/m²) & $23.3 \pm 2.6$ & $23.7 \pm 3.8$ & $24.5 \pm 3.7$ & 0.192 \\
ASA PS classification & & & & $>0.999$ \\
I, II & $49(98)$ & $48(96)$ & $48(96)$ & \\
III & $1(2)$ & $2(4)$ & $2(4)$ & \\
Previous abdominal surgery & $9(18)$ & $5(10)$ & $12(24)$ & 0.511 \\
Onset of symptoms (day) & $1.7 \pm 2.3$ & $0.9 \pm 0.9$ & $1.5 \pm 0.9$ & $0.026^{\mathrm{b}}$ \\
Time to flatus (day) & $1.4 \pm 0.8$ & $1.3 \pm 0.5$ & $1.4 \pm 0.7$ & 0.562 \\
Time to soft diet (day) & $1.7 \pm 1.0$ & $1.6 \pm 0.6$ & $1.7 \pm 1.0$ & 0.739 \\
Length of postoperative & $2.9 \pm 2.1$ & $2.2 \pm 0.7$ & $2.7 \pm 2.6$ & 0.160 \\
$\quad$ hospital stay (day) & & & & \\
Postoperative complications & $3(6)$ & $2(4)$ & $2(4)$ & 0.816 \\
$\quad$ Wound infection or seroma & $3(6)$ & $1(2)$ & $2(4)$ & \\
Intra-abdominal abscess & $0(0)$ & $1(2)$ & $0(0)$ & \\
Length of appendix (cm) & $6.2 \pm 1.9$ & $6.5 \pm 1.3$ & $6.3 \pm 1.3$ & 0.528 \\
Diameter (cm) & $1.5 \pm 0.5$ & $1.4 \pm 0.7$ & $1.7 \pm 0.8$ & 0.131 \\
Surgical failure & $5(10)$ & $4(8)$ & $4(8)$ & 0.919 \\
Readmission within 30 days & $0(0)$ & $1(2)$ & $0(0)$ & $>0.999$ \\
\hline Val
\end{tabular}

Values are presented as number (\%) or mean \pm standard deviation.

BMl, body mass index; ASA PS, American Society of Anesthesiologists physical status. Residents: $A$, first; $B$, second; $C$, third year of training.

${ }^{a} B$ vs. $C, P=0.031 .{ }^{b}$ A vs. $B, P=0.023$. 


\section{Coloproctology $\quad \begin{array}{ll}\text { Annals ofident Learning Curve } & \text { Chang Woo Kim, et al. }\end{array}$}

Table 2. Operative findings

\begin{tabular}{|c|c|c|c|c|}
\hline Operative finding & $A(n=50)$ & $B(n=50)$ & $C(n=50)$ & P-value \\
\hline Operation type & & & & 0.124 \\
\hline Appendectomy & $45(90)$ & $49(98)$ & $49(98)$ & \\
\hline Cecectomy & $5(10)$ & $1(2)$ & $1(2)$ & \\
\hline Operation time (min) & $43.9 \pm 16.2$ & $45.3 \pm 19.6$ & $48.4 \pm 33.0$ & 0.392 \\
\hline Open & $7.9 \pm 2.0$ & $7.8 \pm 3.0$ & $8.4 \pm 3.0$ & 0.474 \\
\hline Intra-abdominal & $23.9 \pm 14.9$ & $26.3 \pm 17.5$ & $27.5 \pm 9.4$ & 0.476 \\
\hline Closure & $12.1 \pm 3.2$ & $11.2 \pm 3.2$ & $12.5 \pm 4.7$ & 0.209 \\
\hline Estimated blood loss (mL) & $0(0-70)$ & $0(0-0)$ & $0(0-5)$ & 0.433 \\
\hline Location of appendix & & & & $<0.001^{\mathrm{a}}$ \\
\hline Prececal or preileal & $5(10)$ & $5(10)$ & $21(42)$ & \\
\hline Subcecal & $31(62)$ & $30(60)$ & $15(30)$ & \\
\hline Retrocecal & $14(28)$ & $12(24)$ & $11(22)$ & \\
\hline Pelvic & $0(0)$ & $3(6)$ & $3(6)$ & \\
\hline Severity of the inflammation & & & & 0.751 \\
\hline Early focal & $11(22)$ & $18(36)$ & $5(10)$ & \\
\hline Suppurative & $20(40)$ & $28(56)$ & $34(68)$ & \\
\hline Gangrenous & $8(16)$ & $2(4)$ & $1(2)$ & \\
\hline Perforated & $11(22)$ & $2(4)$ & $10(20)$ & \\
\hline Perforation & & & & 0.081 \\
\hline None & $39(78)$ & $48(96)$ & $40(80)$ & \\
\hline Base & $4(8)$ & $1(2)$ & $5(10)$ & \\
\hline Middle portion & $2(4)$ & $0(0)$ & $0(0)$ & \\
\hline Tip & $5(10)$ & $1(2)$ & $5(10)$ & \\
\hline Peritonitis & & & & 0.287 \\
\hline None & $32(64)$ & $44(88)$ & $37(74)$ & \\
\hline Localized & $17(34)$ & $6(12)$ & $12(24)$ & \\
\hline Generalized & $1(2)$ & $0(0)$ & $1(2)$ & \\
\hline Fluid collection & & & & 0.139 \\
\hline None & $10(20)$ & $22(44)$ & $6(12)$ & \\
\hline Minimal & $31(62)$ & $22(44)$ & $28(56)$ & \\
\hline Moderate & $8(16)$ & $6(12)$ & $15(30)$ & \\
\hline Profuse & $1(2)$ & $0(0)$ & $1(2)$ & \\
\hline Intraoperative complication & $1(2)$ & $1(2)$ & $2(4)$ & $>0.999$ \\
\hline Bleeding & $0(0)$ & $1(2)$ & $1(2)$ & \\
\hline Small-bowel injury & $1(2)$ & $0(0)$ & $1(2)$ & \\
\hline Conversion & $1(2)$ & $0(0)$ & $1(2)$ & $>0.999$ \\
\hline Drain placement & $11(22)$ & $3(6)$ & $10(20)$ & 0.786 \\
\hline Intervention of supervisor & $3(6)$ & $2(4)$ & $3(6)$ & $>0.999$ \\
\hline
\end{tabular}

Values are presented as number (\%), mean \pm standard deviation, or median (range).

Open, measured time from skin incision to trocar insertion; intra-abdominal, measured time for appendectomy and specimen retrieval; closure, measured time for wound closure.

Residents: A, first; $B$, second; $C$, third year of training.

${ }^{a} A$ vs. $C, P<0.001 ; B$ vs. $C, P=0.001$
(52\%) were male (Table 1). Patients in resident B's group were typically younger than those in resident C's group and had shorter symptom durations than those of patients in resident A's group. The location of the appendix was more likely to be prececal or preileal in resident C's group than among the groups of residents A or B (Table 2). There were no differences in OT for open, closed, or intra-abdominal procedures or overall OT among the 3 groups. The severity levels of inflammation, peritonitis, and intraoperative complications were similar. Perforation of the appendix was found less frequently in resident B's group than in the groups of residents A and C ( $4 \%, 22 \%$, and $20 \%$, respectively), although the difference was not statistically significant $(\mathrm{P}=0.081)$. Resident C's group presented a relatively equal distribution of perforation

Table 3. Risk factors for surgical failure (univariate analysis)

\begin{tabular}{llc}
\hline Variable & \multicolumn{1}{c}{ HR $(95 \%$ Cl) } & P-value \\
\hline Male sex & $2.217(0.652-7.544)$ & 0.202 \\
Age $>40 \mathrm{yr}$ & $1.184(0.378-3.704)$ & 0.772 \\
$\mathrm{BMI}>24 \mathrm{~kg} / \mathrm{m}^{2}$ & $1.167(0.373-3.657)$ & 0.790 \\
ASA PS classification $\geq \|$ & $1.412(0.361-5.522)$ & 0.620 \\
Previous abdominal surgery & $1.487(0.379-5.827)$ & 0.569 \\
Location of appendix & & \\
$\quad$ Antececal & 1 & \\
Paracecal & $0.782(0.122-5.003)$ & 0.795 \\
Retrocecal & $1.706(0.341-8.528)$ & 0.515 \\
Pelvis & $1.333(0.332-5.349)$ & 0.685
\end{tabular}

Severity of the inflammation

$\begin{array}{lll}\text { Early } & 1 & \\ \text { Suppurative } & 2.143(0.241-19.059) & 0.494 \\ \text { Gangrenous } & 7.333(0.595-90.332) & 0.120 \\ \text { Perforated } & 9.167(0.993-84.613) & 0.051 \\ \text { Perforation } & & \\ \text { None } & 1 & \\ \text { Base } & 6.375(1.380-29.449) & 0.018 \\ \text { Middle portion } & 1.929(0.250-14.887) & 0.529 \\ \text { Tip } & 3.306(0.609-17.935) & 0.166\end{array}$

Peritonitis

$\begin{array}{lcc}\text { None } & 1 & \\ \text { Localized } & 2.524(0.747-8.524) & 0.136 \\ \text { Generalized } & 15.143(0.854-268.52) & 0.064\end{array}$

Fluid collection

\begin{tabular}{lll} 
None & 1 & \\
Minimal & $0.254(0.057-1.124)$ & 0.071 \\
Moderate & $1.375(0.358-5.285)$ & 0.643 \\
\hline
\end{tabular}

$\mathrm{HR}$, hazard ratio; $\mathrm{Cl}$, confidence interval; BMI, body mass index; ASA PS, American Society of Anesthesiologists physical status. 
throughout the study period, whereas residents A and B observed perforation more often early on. In particular, resident B performed surgery on only 2 patients with perforated appendicitis as the fifth and 13th cases among her 50 cases.
The postoperative clinical course including complications, hospital stay, and time to soft diet initiation was not different between the groups. Although supervisors intervened and completed 8 cases $(5.3 \%)$ due to reasons such as severe adhesions $(n=5)$, bleed-

Table 4. Comparison between surgeries performed by residents and staff

\begin{tabular}{|c|c|c|c|c|c|}
\hline \multirow{2}{*}{ Variable } & \multicolumn{3}{|c|}{ Before matching } & \multicolumn{2}{|c|}{ After matching } \\
\hline & Resident $(n=150)$ & Staff $(n=239)$ & P-value & Staff $(n=198)$ & P-value \\
\hline Male sex & 78 (52) & $131(54.8)$ & 0.603 & 107 (54) & 0.706 \\
\hline Age (yr) & $40.9 \pm 14.9$ & $28.3 \pm 20.5$ & $<0.001$ & $25.5 \pm 19.0$ & $<0.001$ \\
\hline $\mathrm{BMI}\left(\mathrm{kg} / \mathrm{m}^{2}\right)$ & $23.8 \pm 3.4$ & $21.4 \pm 4.2$ & $<0.001$ & $21.2 \pm 3.9$ & $<0.001$ \\
\hline ASA PS classification & & & 0.525 & & 0.034 \\
\hline I & $123(82)$ & $206(86.2)$ & & $181(91.4)$ & \\
\hline$\|$ & $22(14.7)$ & $24(10)$ & & $12(6.1)$ & \\
\hline III & $5(3.3)$ & $8(3.3)$ & & $5(2.5)$ & \\
\hline IV & $0(0)$ & $1(0.4)$ & & $0(0)$ & \\
\hline Previous abdominal surgery & 26 (17.3) & $20(8.4)$ & 0.010 & $14(7.1)$ & 0.003 \\
\hline Operation type & & & 0.580 & & 0.595 \\
\hline Appendectomy & $143(95.3)$ & $223(93.3)$ & & $191(96.5)$ & \\
\hline Cecectomy & $7(4.7)$ & $15(6.3)$ & & $7(3.5)$ & \\
\hline lleocecectomy & $0(0)$ & $1(0.4)$ & & $0(0)$ & \\
\hline Operation time (min) & $50.1 \pm 29.1$ & $46.0 \pm 26.9$ & 0.165 & $38.3 \pm 13.9$ & $<0.001$ \\
\hline Estimated blood loss (mL) & $0(0-70)$ & $0(0-10)$ & 0.413 & $0(0-5)$ & 0.690 \\
\hline Perforation & & & $<0.001$ & & 0.536 \\
\hline None & $127(84.7)$ & $164(68.6)$ & & $164(82.8)$ & \\
\hline Base & $10(6.7)$ & $21(8.8)$ & & $11(5.6)$ & \\
\hline Middle portion & $2(1.3)$ & 25 (10.5) & & $6(3)$ & \\
\hline Tip & $11(7.3)$ & $29(12.1)$ & & $17(8.6)$ & \\
\hline Peritonitis & & & $<0.001$ & & 0.660 \\
\hline None & $113(75.3)$ & $146(61.1)$ & & $146(73.7)$ & \\
\hline Localized & $35(23.3)$ & $72(30.1)$ & & $47(23.7)$ & \\
\hline Generalized & $2(1.3)$ & $21(8.8)$ & & $5(2.5)$ & \\
\hline Intraoperative complication & $4(2.7)$ & $1(0.4)$ & 0.075 & $0(0)$ & 0.034 \\
\hline Bleeding & $2(1.3)$ & $1(0.4)$ & & $0(0)$ & \\
\hline Small-bowel injury & $2(1.3)$ & $0(0)$ & & $0(0)$ & \\
\hline Conversion & $2(1.3)$ & $3(1.3)$ & $>0.999$ & $1(0.5)$ & 0.580 \\
\hline Length of postoperative hospital stay (day) & $2.6 \pm 2.0$ & $2.9 \pm 1.8$ & 0.103 & $2.4 \pm 1.0$ & 0.345 \\
\hline Postoperative complication & $7(4.7)$ & $28(11.7)$ & 0.028 & $17(8.6)$ & 0.200 \\
\hline Wound infection or seroma & $6(4.0)$ & $18(7.5)$ & & $13(6.6)$ & \\
\hline Intra-abdominal abscess & $1(0.7)$ & $4(1.7)$ & & $3(1.5)$ & \\
\hline lleus & $0(0)$ & $4(1.7)$ & & $1(0.5)$ & \\
\hline Voiding difficulty & $0(0)$ & $2(0.8)$ & & $0(0)$ & \\
\hline Readmission within 30 days & $1(0.7)$ & $7(2.9)$ & 0.160 & $4(2)$ & 0.395 \\
\hline
\end{tabular}

Values are presented as number (\%), mean \pm standard deviation, or median (range).

BMI, body mass index; ASA PS, American Society of Anesthesiologists physical status. 


\section{Coloproctology chang Woo Kim, et al}

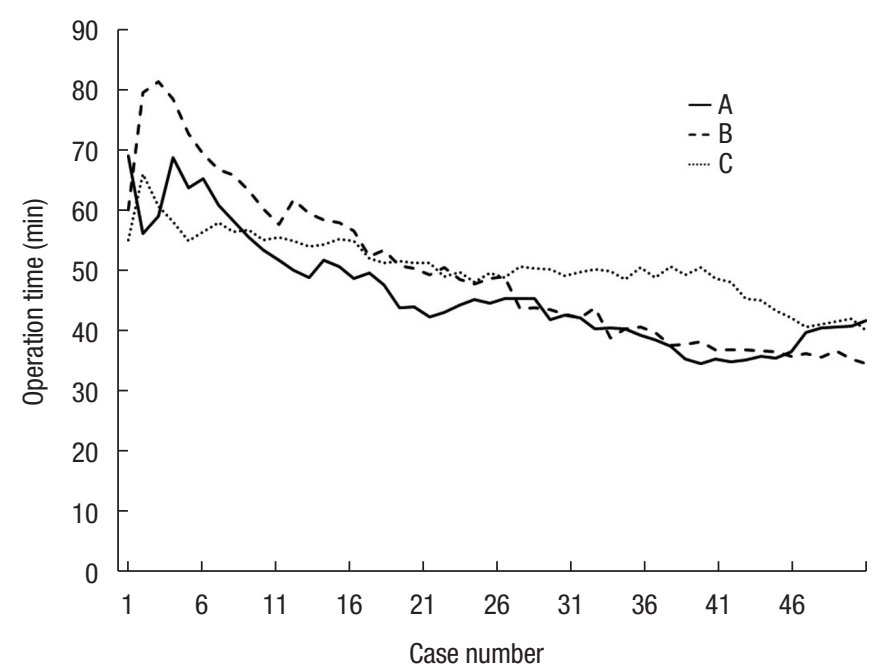

Fig. 1. Moving average method for operation time.

Residents: A, first; $\mathrm{B}$, second; C, third year of training.

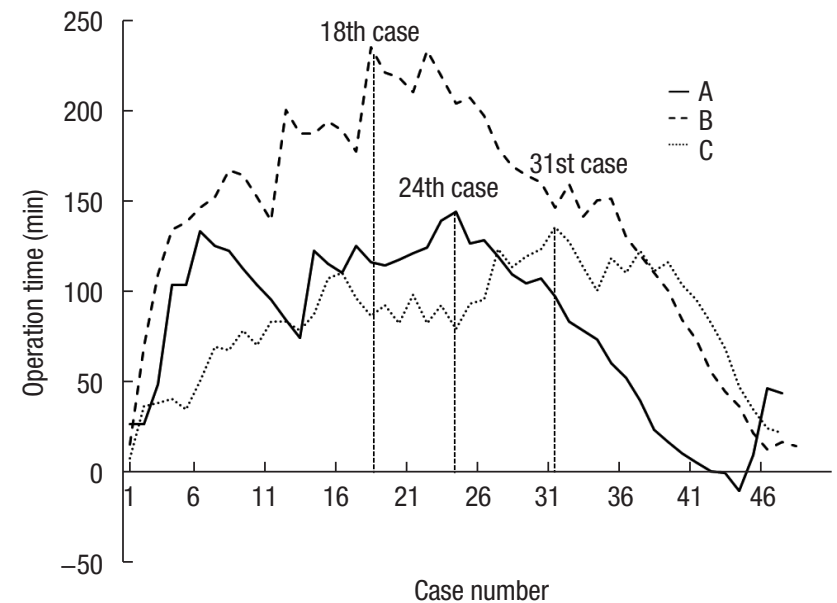

Fig. 2. Cumulative sum control chart for operation time.

Residents: A, first; B, second; C, third year of training.

ing $(\mathrm{n}=2)$, or suspicion of cancer $(\mathrm{n}=1)$, there was no difference in intervention rate by supervisors or surgical failure among the 3 groups. Perforation of the appendix base was the only significant risk factor for surgical failure (Table 3). A multivariate analysis was not performed. The severity of inflammation and generalized peritonitis appeared to affect surgical failure with borderline significance $(\mathrm{P}=0.051$ and $\mathrm{P}=0.064$, respectively).

Patients who underwent surgery performed by staff surgeons were heterogeneous in terms of age, BMI, history of previous abdominal surgery, perforation of the appendix, degree of peritonitis, and postoperative complications when compared with the patients in the residents' groups (Table 4). To adjust for the imbalance in surgical difficulty between these 2 groups, case matching was performed, balancing perforation and peritonitis. After

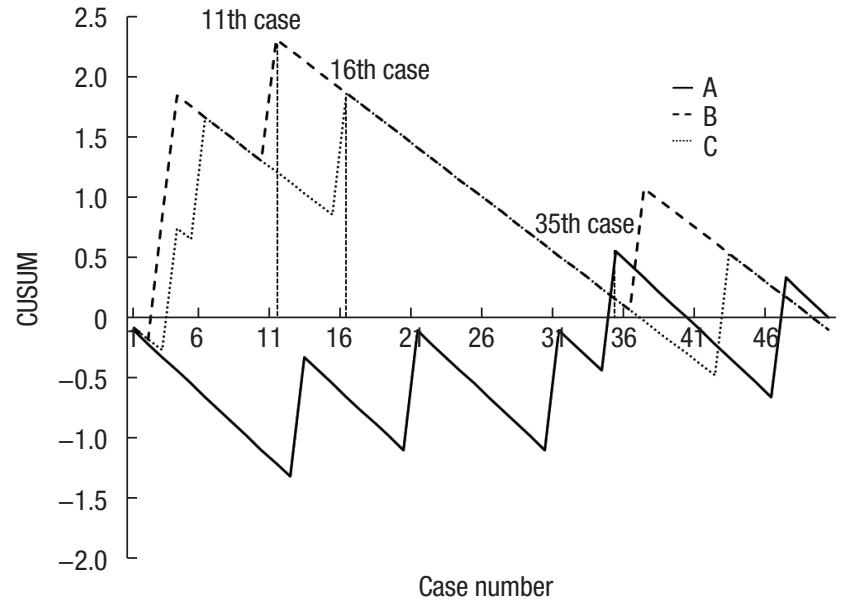

Fig. 3. Cumulative sum control chart for surgical completion. Residents: A, first; B, second; C, third year of training.

matching, OT was 11.8 minutes shorter and fewer intraoperative complications were observed in the staff surgeon patient group when compared with the resident patient group. However, length of postoperative hospital stay, postoperative complications, and readmission rates did not vary between 2 groups.

\section{Learning curve}

The moving average method for OT showed a decreasing tendency for all residents (Fig. 1). CUSUM for OT exhibited peaks at the 24th, 18th, and 31st cases for residents $\mathrm{A}, \mathrm{B}$, and $\mathrm{C}$, respectively (Fig. 2). In terms of surgical failure, residents A, B, and C reached steady states after their 35 th, 11 th, and 16 th cases, respectively (Fig. 3). Although surgical failure rates did not vary significantly among the 3 residents, resident A showed a relatively equal distribution of surgical failure throughout the study period, whereas residents $\mathrm{B}$ and $\mathrm{C}$ both experienced surgical failure earlier on.

\section{DISCUSSION}

Based on evidence that surgical skill level can affect clinical outcomes, various methods have been introduced to evaluate surgical skill [21-23]. Although there are commercially available training systems for minimally invasive surgery such as computer-enhanced laparoscopic training systems, laparoscopic surgical workstations, and virtual reality simulators, limited opportunities may be available to residents due to the high cost and low compatibility of these systems $[24,25]$.

LA has been widely accepted as a parameter to use in evaluating the effectiveness of education and training for surgical residents. First of all, resident involvement did not increase the level of risk to patients, despite past controversy [11-13, 26-28]. Similarly, a comparison of the outcomes between residents and staff surgeons suggested that LA as performed by residents was generally safe 
(Table 4). Although a small difference was noted in OT (50.1 minutes vs. 38.3 minutes, $\mathrm{P}<0.001$ ), this did not significantly affect outcomes and could be overcome by accumulating further experience.

There have been a few studies conducted assessing the LC for LA performed by residents. Kim et al. [15] reported the LC for LA by a single trainee but simply divided the trainee's patients and compared subgroups without appropriate statistical analyses. Elsewhere, Lin et al. [16] analyzed the LC for LA procedures completed by 6 residents but dichotomized and compared patients without any statistical methods and grouped all residents together to analyze the LC, ignoring variations in ability and adaptation of each resident unintentionally. Jaffer and Cameron [29] sought to determine the LC for LA using statistical methods for OT. The LC that they suggested $(n=20)$ was the same as that in the European Association for Endoscopic Surgery (EAES) consensus statement [30]. OT is an important and widely used item in the assessment of LC in many other surgeries, including cholecystectomy, gastrectomy, and colectomy as well as appendectomy. However, it is important to reduce intraoperative or postoperative morbidity as well as to perform the surgery faster. Recent studies have used not only OT but also other parameters to analyze LCs more accurately and objectively. Kim et al. [19] used 4 parameters to assess the LC for single-incision laparoscopic colon cancer surgery, which were conversion, postoperative complications, less than 12 lymph nodes, and local recurrence. Several authors have selected similar methods for various procedures [31,32].

We recruited residents from each grade and employed multidimensional statistical analyses for surgical failure as well as OT to avoid the limitations of previous studies such as a lack of reflection on the advancement of surgical skills and techniques during resident training, reliance on a single resident's experience, inadequate statistical analysis, and OT alone as a parameter. Considering perioperative outcomes from residents at different years of schooling (e.g., first year vs. third year) can facilitate the assessment of how the accumulation of surgical experience affects the LC, and we hypothesized that senior residents would show mastery of the procedure earlier on than junior residents. In terms of OT, the third-year resident (resident C) reached a steady state for his OT last, although the gap was only 5 minutes, whereas the first-year resident $(\mathrm{A})$ reached her steady state last in terms of surgical failure (Figs. 2, 3). Although the senior resident went relatively slow and more strongly pursued the completeness of surgery compared to the junior resident, this difference suggests that the accumulation of surgical experience could affect surgical completion rather than OT.

Based on the accumulation of "assistance-experience" of residents during their residency training with similar "performanceexperience" (i.e., they had similar experiences with LA as an operating surgeon before starting the study), we carefully suggest that increased assistance-experience could help residents adapt to surgery and become stable earlier on in their schooling, although collecting performance-experience is definitely important as well. Resident $\mathrm{B}$ performed at a proficient level sooner than A and C in terms of both OT and surgical failure. However, the gap between residents $\mathrm{B}$ and $\mathrm{C}$ was only 5 cases in terms of surgical failure, whereas the gap between resident A and residents B or C was 19 to 24 cases (Fig. 3). In addition, only 2 of resident B's patients underwent LA for perforated appendicitis, whereas residents $A$ and $C$ performed LA in patients presenting with perforated appendicitis in 10 and 11 cases, respectively. Further, resident B performed the 2 perforated LA cases as her fifth and 13th cases and showed 3 surgical failures before her 11th case, whereas resident $\mathrm{C}$ showed a relatively equal distribution of perforation of the appendix but experienced 3 surgical failures before his 16th case.

One of the limitations of CUSUM is dependence on the sequence of events. In terms of surgical failure, if a resident experiences surgical failure only early on, his or her CUSUM would yield better results. In other words, easier cases were predominant later in the study period for resident $B$ and, consequently, surgical failure was rare. In contrast, although relatively more difficult cases were evenly distributed throughout the study period for resident $C$, he rarely experienced surgical failure later in the study period. This difference is also due to the approach of nonrandomization without stratification of potential influencing factors and could explain why resident B reached a steady state for OT earlier on than her senior, resident $\mathrm{C}$. We sought to identify factors for surgical failure but found that only basal appendix perforation was significantly associated. However, when inflammation and peritonitis were more severe, the surgery was more difficult to conduct, which could affect the surgical failure risk despite a lack of significance in this study (Table 3 ).

To the best of our knowledge, this is the first comparative study to assess the LC for LA performed by residents according to the level of seniority in training using a multidimensional analysis approach. However, some limitations are inevitable. First, randomization was not performed, so a higher level of evidence could not be attained. Specifically, various factors can cause an imbalance in the difficulty of the surgery, such as BMI, location of the appendix, and perforation, and these factors need to be stratified for true randomization. Second, the emphasis placed on patient safety could possibly influence the enrollment of relatively easier cases despite the very small number of excluded patients (6.1\%; 22 and 6 patients were suspected to have intra-abdominal abscess and malignancy on imaging studies, respectively). Third, the definition of surgical failure could be subjective because the concept of surgical completion varies from surgeon to surgeon. Fourth, the sample size was small and only one resident in each grade was recruited for this study, and there is the possibility that certain residents were technically more able than others. If more residents participated in a randomized controlled trial, it is expected that we could obtain a more solid conclusion. LC may be influenced not only by the surgical abilities of individuals but also their personal characteristics. Lastly, the relatively lower BMI of Asian pa- 
tients could affect the accuracy of generalization of our results to other populations.

In conclusion, the resident LC for LA was 11 to 35 cases according to multidimensional statistical analyses. Senior residents tended to show mastery of the procedure earlier than their junior counterparts. The accumulation of surgical experience among residents may affect the LC for surgical completion but not that for OT. Although the experience of surgical assistance is thought to be less important than that of surgical performance in surgical resident training, such may still help to improve surgical completion rates and shorten the LC.

\section{CONFLICTS OF INTEREST}

No potential conflicts of interest relevant to this article exist.

\section{ACKNOWLEDGMENTS}

This work was supported by a National Research Foundation of Korea (NRF) grant funded by the Korean Government Ministry of Education (No. 2017R1D1A1B03030948). This work was first presented as an electronic poster at the 25th International Congress of the European Association of Endoscopic Surgery held June 14-17, 2017 in Frankfurt, Germany.

\section{REFERENCES}

1. Statistics Korea. The top 20 surgeries in 2015. Daejeon (KR): Statistics Korea; [cited 2017 Aug 15]. Available from: http://kostat. go.kr/wnsearch/search.jsp.

2. Neal GE, McClintic EC, Williams JS. Experience with laparoscopic and open appendectomies in a surgical residency program. Surg Laparosc Endosc 1994;4:272-6.

3. Duff SE, Dixon AR. Laparoscopic appendicectomy: safe and useful for training. Ann R Coll Surg Engl 2000;82:388-91.

4. Noble H, Gallagher P, Campbell WB. Who is doing laparoscopic appendicectomies and who taught them? Ann R Coll Surg Engl 2003;85:331-3.

5. Chiu CC, Wei PL, Wang W, Chen RJ, Chen TC, Lee WJ, et al. Role of appendectomy in laparoscopic training. J Laparoendosc Adv Surg Tech A 2006;16:113-8.

6. Semm K. Endoscopic appendectomy. Endoscopy 1983;15:59-64.

7. Frazee RC, Roberts JW, Symmonds RE, Snyder SK, Hendricks JC, Smith RW, et al. A prospective randomized trial comparing open versus laparoscopic appendectomy. Ann Surg 1994;219:725-8.

8. Laine S, Rantala A, Gullichsen R, Ovaska J. Laparoscopic appendectomy-is it worthwhile? A prospective, randomized study in young women. Surg Endosc 1997;11:95-7.

9. Merhoff AM, Merhoff GC, Franklin ME. Laparoscopic versus open appendectomy. Am J Surg 2000;179:375-8.

10. Moberg AC, Berndsen F, Palmquist I, Petersson U, Resch T, Montgomery A. Randomized clinical trial of laparoscopic versus open appendicectomy for confirmed appendicitis. Br J Surg 2005; 92:298-304.

11. Graat LJ, Bosma E, Roukema JA, Heisterkamp J. Appendectomy by residents is safe and not associated with a higher incidence of complications: a retrospective cohort study. Ann Surg 2012;255: 715-9.

12. Jolley J, Lomelin D, Simorov A, Tadaki C, Oleynikov D. Resident involvement in laparoscopic procedures does not worsen clinical outcomes but may increase operative times and length of hospital stay. Surg Endosc 2016;30:3783-91.

13. Singh P, Turner EJ, Cornish J, Bhangu A; National Surgical Research Collaborative. Safety assessment of resident grade and supervision level during emergency appendectomy: analysis of a multicenter, prospective study. Surgery 2014;156:28-38.

14. Man E, Nemeth T, Geczi T, Simonka Z, Lazar G. Learning curve after rapid introduction of laparoscopic appendectomy: are there any risks in surgical resident participation? World J Emerg Surg 2016;11:17.

15. Kim SY, Hong SG, Roh HR, Park SB, Kim YH, Chae GB. Learning curve for a laparoscopic appendectomy by a surgical trainee. J Korean Soc Coloproctol 2010;26:324-8.

16. Lin YY, Shabbir A, So JB. Laparoscopic appendectomy by residents: evaluating outcomes and learning curve. Surg Endosc 2010;24:125-30.

17. Song HS, Jung KH, Ha DY, Jung BO, Jung HG, Lee K. 50 Cases of laparoscopic appendectomy by one surgical resident: the learning curve and safety. J Korean Soc Endosc Laparosc Surg 2010;13:5963.

18. Zollinger RM Jr, Ellison EC. Zollinger's atlas of surgical operations. 9th ed. New York: McGraw-Hill Medical; 2011.

19. Kim CW, Kim WR, Kim HY, Kang J, Hur H, Min BS, et al. Learning curve for single-incision laparoscopic anterior resection for sigmoid colon cancer. J Am Coll Surg 2015;221:397-403.

20. Kim CW, Han YD, Kim HY, Hur H, Min BS, Lee KY, et al. Learning curve for single-incision laparoscopic resection of right-sided colon cancer by complete mesocolic excision. Medicine (Baltimore) 2016;95:e3982.

21. Reznick RK, MacRae H. Teaching surgical skills: changes in the wind. N Engl J Med 2006;355:2664-9.

22. Martin JA, Regehr G, Reznick R, MacRae H, Murnaghan J, Hutchison C, et al. Objective structured assessment of technical skill (OSATS) for surgical residents. Br J Surg 1997;84:273-8.

23. Fried GM, Feldman LS, Vassiliou MC, Fraser SA, Stanbridge D, Ghitulescu G, et al. Proving the value of simulation in laparoscopic surgery. Ann Surg 2004;240:518-25.

24. Chmarra MK, Grimbergen CA, Dankelman J. Systems for tracking minimally invasive surgical instruments. Minim Invasive Ther Allied Technol 2007;16:328-40.

25. Seymour NE, Gallagher AG, Roman SA, O’Brien MK, Bansal VK, Andersen DK, et al. Virtual reality training improves operating room performance: results of a randomized, double-blinded study. Ann Surg 2002;236:458-63. 
26. Scarborough JE, Bennett KM, Pappas TN. Defining the impact of resident participation on outcomes after appendectomy. Ann Surg 2012;255:577-82.

27. Fujita T. Which Is responsible for appendectomy outcomes: attending surgeon, resident, or their communication lack? Ann Surg 2017;265:e28.

28. Davis SS Jr, Husain FA, Lin E, Nandipati KC, Perez S, Sweeney JF. Resident participation in index laparoscopic general surgical cases: impact of the learning environment on surgical outcomes. J Am Coll Surg 2013;216:96-104.

29. Jaffer U, Cameron AE. Laparoscopic appendectomy: a junior trainee's learning curve. JSLS 2008;12:288-91.

30. Neugebauer E, Troidl H, Kum CK, Eypasch E, Miserez M, Paul A.
The E.A.E.S. Consensus Development Conferences on laparoscopic cholecystectomy, appendectomy, and hernia repair. Consensus statements: September 1994. The Educational Committee of the European Association for Endoscopic Surgery. Surg Endosc 1995;9:550-63.

31. Tekkis PP, Senagore AJ, Delaney CP, Fazio VW. Evaluation of the learning curve in laparoscopic colorectal surgery: comparison of right-sided and left-sided resections. Ann Surg 2005;242:83-91.

32. Bege T, Lelong B, Esterni B, Turrini O, Guiramand J, Francon D, et al. The learning curve for the laparoscopic approach to conservative mesorectal excision for rectal cancer: lessons drawn from a single institution's experience. Ann Surg 2010;251:249-53. 